\title{
Quantitative equilibrium test and complementary studies in patients with vertigo
}

\begin{abstract}
Vestibular stimulus provoked from the head is transmitted through the vestibular nerve to the vestibular homo-lateral cell and directly to the brain. At this level the synapse is the origin of the vestibular-spinal tract and the connection of the inferior vestibular nucleus to the cells of the anterior horn through the extension of the fascicular branch. The system of nystagmus generation or the central vestibular system begins in the peripheral nerve cell or the first neuron that is found in the ganglion. The central axon of the Escarpa ganglion extends to the nodular and flocular area to inform the brain. It is transported along the superior vestibular branch of nerve VIII, which connects the vestibular periphery of the utricle, the upper and lateral canal with the 4 vestibular nuclei and the cerebellum.
\end{abstract}

Objective: The present study is motivated to investigate the vestibular function through vestibulospinal (CCG) and (TOB), retinoocular and vestibular (CNG) studies and cerebral vascular circulation through USD Doppler Ultrasonography in the patient With vertigo, in order to determine and better guide the vestibular diagnosis. Describing the results in groups of patients from Germany, Argentina and Mexico.

Materials and Methods: We studied 1343 patients with vertigo, 860 women and 483 men. Mean age was 47.15 years for both, through vestibulospinal (CCG) and (TOB), retinoocular and vestibular studies $(\mathrm{CNG})$ and vascular circulation Cerebral cortex through USD Doppler Ultrasonography in the Otologic Neurophysiology clinic of Mexico City, were studied and investigated under the parameters of Germany 10,335 and Argentina 2,234.

Results: 1343 patients with vertigo or dizziness were investigated. It was found that $48.16 \%$ of the cases had a vascular origin, prevailing a group of pathologies secondary to the process of hydrodynamic alterations. The most frequent symptom of vertigo was sensation of ascent with $59.05 \%$, followed by inclination and sensation of fall $51.04 \%$; And feeling sick $39.02 \%$ in the Mexican group. The different variables for each group are described.

Conclusion: Craniocorpography (CCG), Posturography (TOB), Electronystagmography ENG, Rotatory Test (RIT), Optokinetic Test, Caloric Test and Doppler Ultrasonography are techniques to study patients with vertigo in Mexico, Germany and Argentina.

Keywords: vertigo, cranioocorpography, posturography, computerized electrony stagmography, rotatory test, doppler ultrasound, head and neck
Volume 7 Issue I - 2017

\author{
Saíd Jorge \\ Gabinete De Neurofisiologia Otologica, Mexico
}

Correspondence: Saíd Jorge, Gabinete De Neurofisiologia Otologica, Av. Ejército Nacional \# 42 Int. I-E, Col.Anzures, Delegación Miguel Hidalgo, CP.I I59, Mexico,

Email saidmjorge@gmail.com

Received: May 22, 2017| Published: June 09, 2017

\section{Introduction}

The diagnosis of patients in modern neuro-neurological centers must include not only medical history and physical examination, but also objective and quantitative tests through tests that evaluate equilibrium systems. ${ }^{1-6}$

Several useful studies have been reported in the evaluation of nystagmus that may be spontaneous and inductive, any of which have been given to study vestibular function through the vestibulospinal, retinoocular, and vestibular systems..$^{7-8}$ Through the test of the SkullBody-Spray (CCG), Posturography (TOB) tests, and Computerized Electronystagmography $(\mathrm{CNG}) \cdot{ }^{10-16}$

1343 patients with vertigo or dizziness are investigated; $48.16 \%$ of the cases have a vascular origin, prevailing a group of pathologies secondary to the process of hydrodynamic alterations, 10,335 patients were studied and investigated under German parameters. Argentina 2,234 patients. Through the Doppler Ultrasonography of the head and neck (USD), the modern physician can help to complement his better diagnosis, correlating the clinical exploration with vestibulospinal (CCG) and (TOB), retinoocular And vestibulocular (CNG)] of the patient with vertigo or dizziness. ${ }^{17,23}$
The present study is motivated to investigate the vestibular function through the $\mathrm{CCG}$, TOB, $\mathrm{CNG}$ and cerebral vascular circulation through the Doppler ultrasound USD's in the patient with vertigo, in order to determine and To better guide the vestibular diagnosis..$^{24-32}$

\section{Material and methods}

We reviewed the medical records of patients with a diagnosis of vertigo valued at Gabinete de Neurofisiología Otologíca from 1993-2016, finding 1,343 patients. It was recorded: sex, age, reason for consultation, audiological results, otoneurological and vascular studies.

A detailed questionnaire NODEC IV (Germany) (10,335 patients) and the ENT- Neurootofisiología Oftalmológica Examination (Argentina) (2,234 patients) were applied to each patient. The neurological study and its characteristics were practiced in all cases. Cranial nerve disorders as well as background of underlying diseases were considered. In this case of vertigo.

\section{For the study of Craniocorpography (GCC)}

The patient is blindfolded by a sleeping mask, so the visual stimulus is cut off, the patient loses contact with the floor, is asked to do 80 
steps in place while the proprioceptive stimuli intensify little to Little also, therefore, the patient now maintains the balance in the stimulus received from the two only vestibular systems we study the deviation and rotation of the body giving results of peripheral or central systems as well as their interpretations. The test procedures applied are the test of Romberg's position and the Unterberger-Fukuda gait, the following variables are studied:

a. The longitudinal displacement of the starting point to the final point.

b. The lateral rolling that is the width of the envelope of the movement of the curved head.

c. The angular deviation, which is the angle between the direction of the starting point and the end point.

d. The body of rotation which is the rotation around the axis of the body.

\section{To perform the Posturography (TOB) test}

In all patients, the balance test (TOB) was performed, consisting of a static platform of $50 \times 50 \mathrm{~cm}$, where the patient stands out above, which has four pressure sensors (one at each corner) with a force range of 0 to $100 \mathrm{~kg}$ each. Each sensor produces a small voltage proportional to the pressure. The platform maintains the electronics necessary to amplify these signals, convert them to digital format and send the information to a computer, using the serial port. The computer receives the forming information from each pressure sensor.

The special software that runs on the Windows PC, allows the complete COG calculation and its subsequent analysis suppose a platform that is raised on the ground, with four pressure sensors: 1,2,3 and 4 With the patient standing again, each sensor receives a pressure or force.

\section{The condition of the test is:}

a. Test 1: Open eyes, stable surface (EOS): Complete balance information.

b. Test 2: With eyes closed, surface stable (ECS): somato sensorial and vestibular information.

c. Test 3: Open eyes unstable surface (SOU): visual and vestibular information

d. Test 4: Eyes closed, unstable surface (ECU): Single vestibular information

The unstable condition (suppressed or very attenuated tactile information) is performed using a thick foam pad on the platform.

A polygraphic mapping of the patient's nystagmus is done through Computerized Electronystagmography (CNG), using electrodes paired through different axes of movement (horizontal and vertical) of the eyes, a signal amplification system and recording the graphs in weather. By convention, the electrodes are arranged so that an upward deflection of the needle indicates either to the left or a downward nystagmus beat.

The obtained electronystagmography carefully studies the coordinated or dissociated movements of the eyes. Nystagmus is identified in number, frequency, start point, culmination time and its fine characteristics are taken into account; Spontaneous nystagmus, slow phase of nystagmus, saccadic eye movements, eye tracking, and optokinetic testing. A complete battery of various balance tests is based on the analysis of nystagmus by quantifying its responses. Vestibular ocular tests are performed either in monoaural form by means of caloric or binaural stimuli through inertial stimuli such as a rotating chair.

\section{The Diagram of the Butterfly of Claussen}

In order to maintain stable background conditions during the caloric test, the irrigation catheters are inserted to the outer ears using an air irrigator. The optimum flow rate should be maintained between 5 to 6 liters per minute. This flow is maintained for half a minute at $27^{\circ} \mathrm{C}\left(30^{\circ} \mathrm{C}\right)$ or $48^{\circ} \mathrm{C}\left(44^{\circ} \mathrm{C}\right)$. The test is performed supine with the patient lying on a special research table with the head elevated by 30 degrees.

The nystagmus reaction is recorded electronystagmographically for at least 3 minutes and these nystagmus responses are taken as a measure of the individual's reaction on a standard test load. In a first work upwards, the curves are evaluated by identifying the nystagmus. This makes heartbeat. Therefore, the post-caloric culmination takes place. The maximum heartbeat frequency for 30 seconds in the culmination area, which is called the central nystagmus frequency, is then transferred into the schematic of the 4-quadrant butterfly with underlying normal ranges for the development of functional characteristics of the Right and left hot caloric irrigation and the right and left caloric cold responses.

The rotational nystagmus test uses a binaural stimulus.

Optokinetic nystagmus is stimulated through the retinoocular pathway and recorded by electronystagmography. Through the use of the polygraph of the electronystagmography the right and left eye movements are evaluated and can be carefully analyzed and evaluated for the ocular coordination deficit. In order to know the basic ocular activity, we regularly carry out a spontaneous nystagmus with eyes closed and a nystagmus-fixation before the optokinetic test. We perform a pendulum-tracking stimulus of the gaze, the patient is looking at The oscillation of the electronic bar that generates a pendulum-shaped physical pendulum at a distance of $1 \mathrm{~m}$ in front of its eyes, $20^{\circ}$ to the right and $20^{\circ}$ to the left, with a frequency of 0.3 degrees.

Circulatory hydrodynamics was studied by means of the two methods, Doppler Ultrasonography (USD), the effect of internal and external carotid arteries, supratrochlear, right and left vertebrae and anterior cerebral right and left. Head and neck cerebral blood pressure was investigated using a bidirectional fluxmeter from the Sonothecnic Germany 7000 continuous beam with probes and a Mhz frequency 2, 4 and 8.

The method consists of supporting a probe with a pencil shape that is capable of emitting signals at a given frequency (according to the depth of the artery being studied) over and through the different arteries, the signals being reflected by the Column of red blood cells within the circulation, causing a change in the emitted frequency, which allows us to evaluate the velocity, flow and direction of the bloodstream in a secondary way.

The obtained analogue signal is analyzed through a microcomputer evaluating graphically the following parameters:
a. Maximum systolic velocity (MSS in $\mathrm{cm} / \mathrm{sec}$ )
b. Final Diastolic Velocity (SDS in $\mathrm{cm} / \mathrm{sec}$ )
c. Resistance Rate (IR according to Pourcelot formula)

The mean brachial pressure consists of the evaluation of the maximum and minimum blood pressure taken at the level of the brachial artery or the left humeral artery. For this, a sphygmomanometer of the brand OMRON, HEM-714INT was used. The bracelet is placed in the 
region or the inner border of the arm and the values corresponding to systolic and diastolic arterial values are recorded. The above values were taken in a sitting and lying position (Proof of Provocation) that allow this method to obtain an orientation of peripheral arterial capillary resistance in a fast manner. Claussen, Bergmann and Bertora have reported the most important parameters for diagnosis in CCG, CNG, TOB and USD. Each GCC, GNC, TOB and UDS variable was analyzed using statistical tests (Chi-Square and Pearson's R) and Spearman's independent variables for correlation were applied. ${ }^{33}$

\section{Results}

1343 patients at the Gabinete de Neurofisiología Otologíca in Mexico City, 860 women and 483 men, mean age was 47.15 years. NODEC IV (Germany, 10,335 patients) and Neurootofisiología Oftalmológica (Argentina, 2,234 patients) were examined and investigated, ENG, ENG, CCG, TOB and USD. The distribution of sex, age and symptoms for the groups is shown in Table 1.

The most frequent symptom of vertigo was sensation of ascent with $59.05 \%$, followed by inclination and sensation of fall $51.04 \%$; And feeling sick $39.02 \%$. We found hypoacusia in $53.30 \%$ for NODEC IV (Germany) and 54.58\% for Gabinete Neurofisiología Otologíca (Mexico). The symptom tinnitus 44.80 (Germany) 43\% Argentina and $42.94 \%$ Mexico is similar in all three groups, Table 2. The headache was $35.66 \%$ in Mexico, similar to Neurootofisiología Oftalmológica (Argentina), but greater than NODEC IV. Table 3. In vascular history: hypertension $24.20 \%$ (Mexico) was as high as Neurootofisiología Oftalmológica (Argentina) but less than NODEC IV (Germany). For NODEC IV (Germany) Heart Failure 0.67\%, Neurology Disease $7.15 \%$, and kidney disease $9.95 \%$ were less than

Table I Distribution of patients by age, gender, symptoms for Neurootofisiología Oftalmológica (Argentina), However, Diabetes is the highest for Mexico $9.75 \%$ not so for the NODEC IV group (Germany) and the Neurootofisiología Oftalmológica (Argentina), Table 4.

The results found among the groups can be due to the cultural, educational and alimentary habits of each country, an example can be the drinks: in Mexico the food is accompanied by soft drinks, in Germany of beer and in Argentina with wine.

In the results of the Cranioocorpography study the variable of linear displacement, right and left lateral deviation, right and left lateral angulation are similar with the NODEC IV (Germany) and Neurootofisiología Oftalmológica (Argentina) groups Table 5. In the Romberg test we found for Mexico that the normal variable is $73.42 \%$ Table 6 . The discrete ataxic variable for the Mexican group is $18.61 \%$, and for Otoophthalmologic Neurophysiology (Argentina) it is $29.26 \%$. This may be due to the high diagnosis of central vertigo in this country.

In the Caneocorpography Equilibrium Test (GCC) the results of the variables (mean velocity, total displacement, equilibrium area and Romberg) are shown in Table 7. The variables of caloric and rotatory tests are similar for all groups Table 8 . In the results of the Optokinetic Test we find the values of the variables frequency, amplitude and speed slow phase Table 9. We studied and described the normal values of head and neck arteries in a group of 750 patients through Doppler ultrasonography (USD) of the internal and external carotid arteries, supratrochlear, vertebral and right anterior cerebral cerebral. In order to standardize the test in Mexico and thus apply it to patients with vértigo Table 10

\begin{tabular}{llll}
\hline & Nodec Iv. (Germany) & Ophthalmologic Neurootophysiology (Argentina) & Neurophysiology Otology (Mexico) \\
\hline \# Patient & 10,335 & 2,234 & 1,343 \\
Age & 42.2 & 48.05 & 47.15 \\
Female sex & 45.2 & 55.49 .05 & 49.1 \\
Male sex & 54.8 & $44.5 \mathrm{I}$ & 45.07 \\
Symptom & & & \\
Lift sensation & $39.10 \%$ & $14.91 \%$ & $59.05 \%$ \\
Rotation sensation & $35.90 \%$ & $33.06 \%$ & $51.04 \%$ \\
Feeling sick & $30.10 \%$ & $29.24 \%$ & $39.02 \%$ \\
Lateral sensation & $19.20 \%$ & $26.93 \%$ & $34.34 \%$ \\
Insecurity & $35.20 \%$ & $60.92 \%$ & $26.88 \%$ \\
Vomit & $15.10 \%$ & $14.10 \%$ & $13.85 \%$ \\
Cold sweating & $11.90 \%$ & $21.04 \%$ & $10.87 \%$ \\
\hline
\end{tabular}

Table 2 Distribution of auditory symptoms

\begin{tabular}{llll}
\hline Symptom & Nodec iv (Germany) & Ophthalmologic Neurootophysiology (Argentina) & Neurophysiology Otology (Mexico) \\
\hline Hypoacusia & $53.30 \%$ & $33.87 \%$ & $54.58 \%$ \\
Tinnitus & $44.80 \%$ & $43 \%$ & $42.94 \%$
\end{tabular}

Table 3 Distribution of visual and head symptoms

\begin{tabular}{lllc}
\hline Symptom & NODEC IV (GERMANY) & Ophthalmologic Neurootophysiology (Argentina) & Neurophysiology Otology (Mexico) \\
\hline Double vision & $26.93 \%$ & $9.64 \%$ & $5.96 \%$ \\
Oscilopsia & $\ldots . .$. & $28.66 \%$ & $4.99 \%$ \\
Headache & $10.50 \%$ & $47.10 \%$ & $35.66 \%$ \\
\hline
\end{tabular}

Table 4 Distribution of vascular symptoms

\begin{tabular}{llll}
\hline Background & NODEC IV (Germany) & Ophthalmologic Neurootophysiology (Argentina) & Neurophysiology Otology (Mexico) \\
\hline Hypotension & $23.50 \%$ & $20.92 \%$ & $16.60 \%$ \\
Hypertension & $12.40 \%$ & $20.34 \%$ & $24.20 \%$ \\
Insuficience heart & $11.30 \%$ & $4.85 \%$ & $0.67 \%$ \\
Diseases Neurological & $23 \%$ & $12.83 \%$ & $7.15 \%$ \\
Head trauma & $24 \%$ & $17.34 \%$ & $16.45 \%$ \\
Diabetes & $5.10 \%$ & $3.23 \%$ & $9.75 \%$ \\
Kidney diseases & $6.30 \%$ & $3.46 \%$ & $3.95 \%$ \\
\hline
\end{tabular}


Table 5 Distribution of the variables Unterberger test

\begin{tabular}{llll}
\hline Craniocorpograhy Test & NODEC IV (Germany) & Ophthalmologic Neurootophysiology (Argentina)Neurophysiology Otology (Mexico) \\
\hline \# PATIENTS & $\mathrm{I} .689$ & $\mathrm{I} .200$ & $\mathrm{I} .343$ \\
\multicolumn{2}{l}{ Body movement, Side by side (CM) I5.I0 } & 14.93 & 18.45 \\
Displacement Lineal (CM) & $\mathrm{I} 10.80$ & 104.80 & $95.1 \mathrm{I}$ \\
LAT.DEV. Right (GRD) & 33.40 & 36.72 & 33.07 \\
LAT.DEV. Left (GRD) & 32.40 & 36.72 & 33.07 \\
LAT.ANG Right (GRD) & $56.50 \%$ & $58.42 \%$ & 56.12 \\
LAT.ANG Left (GRD) & $51.90 \%$ & $53.83 \%$ & 52.70 \\
\hline
\end{tabular}

Table 6 Distribution of Romberg test variables

\begin{tabular}{lll}
\hline Test of Romberg (Qualitative) & Ophthalmologic Neurootophysiology (Argentina) & Neurophysiology Otology (Mexico) \\
\hline \# PATIENTS & 1.200 & 1.343 \\
NORMAL & $43.69 \%$ & 73.42 \\
DISCRET ATAXIC<8 CM & $29.26 \%$ & 18.62 \\
SEVERE ATAXIC<IO CM & $28.04 \%$ & 7.97 \\
\hline
\end{tabular}

Table 7 Distribution of Craniocorpography Test (GCC)

\begin{tabular}{|c|c|c|c|}
\hline \multicolumn{4}{|c|}{ Variables and Average Speed } \\
\hline \multicolumn{2}{|c|}{ Stable } & \multicolumn{2}{|l|}{ In Stable } \\
\hline $\mathrm{OA}<.40$ & I & $O A<.69$ & 5 \\
\hline$O A>1.13$ & 19 & $O A>2.13$ & 14 \\
\hline Total & 20 & Total & 19 \\
\hline$O C<.94$ & 49 & $O C<1.61$ & 41 \\
\hline$O C>1.53$ & 22 & $O C>3.64$ & 8 \\
\hline Total & 71 & Total & 49 \\
\hline Anormal & 91 & Anormal & 68 \\
\hline Normal & 8 & Normal & 32 \\
\hline Total & 100 & Total & 100 \\
\hline \multicolumn{4}{|c|}{ Variables and Balance Area } \\
\hline Stable & & In Stable & \\
\hline $\mathrm{OA}<.82$ & 7 & $\mathrm{OA}<.78$ & I \\
\hline $\mathrm{OA}>2.50$ & 47 & $\mathrm{OA}>4.68$ & 48 \\
\hline Total & 54 & Total & 49 \\
\hline$O C<1.93$ & 26 & OC $<4.91$ & 31 \\
\hline OC >7.09 & 10 & $O C>20.13$ & II \\
\hline Total & 36 & Total & 42 \\
\hline Anormal & 90 & Anormal & 91 \\
\hline Normal & 10 & Normal & 9 \\
\hline Total & 100 & Total & 100 \\
\hline \multicolumn{4}{|c|}{ Variables Romberg } \\
\hline Estable & & In estable & \\
\hline $\mathrm{OA}<244$ & 88 & $\mathrm{OA}<89$ & 99 \\
\hline $\mathrm{OA}>443$ & 12 & $O A>99$ & I \\
\hline Total & 100 & Total & 100 \\
\hline Anormal & 47 & Anormal & 49 \\
\hline Normal & 3 & Normal & 1 \\
\hline Total & 50 & Total & 50 \\
\hline
\end{tabular}

Table 8 Caloric and rotatory test results

\begin{tabular}{lllc}
\hline Caloric Test.Frec NYSRA. 30SEG & NODEC IV (Germany) & Ophthalmologic Neurootophysiology (Argentina) Neurophysiology Otology (Mexico) \\
\hline DO NOT. OF PATIENTS & 10,335 & 2,234 & 1,343 \\
$44{ }^{\circ} \mathrm{C}$ LAW & $20,90-57,70$ & $17,83-85.84$ & $20,30-68,04$ \\
$44{ }^{\circ} \mathrm{C}$ LEFT & $25,60-64,00$ & $19,38-75,84$ & $22,20-68,95$ \\
$30^{\circ} \mathrm{C}$ RIGHT & $23,10-60,90$ & $10,30-68,60$ & $19,60-60,67$ \\
$30^{\circ} \mathrm{C}$ LEFT & $24,20-66.80$ & $25,50-80,30$ & $23,90-69,53$ \\
\hline
\end{tabular}

Table 9 Results of Optokinetic Test Variables in the Mexico group

\begin{tabular}{lll}
\hline & Optokinetic Right & Optokinetic Left \\
\hline Frequency / Sec & 60.69 & 62.33 \\
Amplitude u /V & 359.33 & 379.33 \\
SPV/Sec & 17.24 & 18.34 \\
\hline
\end{tabular}

Citation: Jorge S. Quantitative equilibrium test and complementary studies in patients with vertigo.J Neurol Stroke. 20I7;7(I):I-6.

DOI: I0.15406/jnsk.2017.07.00225 
Table 10 Normal blood flow in the extracranial and transcranial arteries in Doppler Ultrasonography in the Mexico group

\begin{tabular}{|c|c|c|c|c|c|c|c|c|}
\hline \multirow[b]{2}{*}{$\mathrm{cm} / \mathrm{sec}$} & \multicolumn{2}{|c|}{ Right Supratclear } & \multicolumn{2}{|c|}{ Supratoclear Left } & \multicolumn{2}{|c|}{ Vertebral Right } & \multicolumn{2}{|c|}{ Vertebral Left } \\
\hline & MVS & VDF & MVS & VDF & MVS & VDF & MVS & VDF \\
\hline average & 28.27 & 7.23 & 27.38 & 7.61 & $|5.4|$ & 4.40 & 14.24 & 3.97 \\
\hline SD & 7.87 & 2.66 & 7.62 & 3.43 & 6.86 & 2.69 & 7.08 & 2.14 \\
\hline$(+)$ & 36.14 & 9.89 & 35.00 & 11.04 & 22.28 & 7.09 & 21.32 & 6.12 \\
\hline$(-)$ & 20.41 & 4.58 & 19.76 & 4.18 & 8.55 & I.7I & 7.17 & 1.83 \\
\hline \multirow[t]{2}{*}{ IR } & 0.74 & & 0.72 & & 0.71 & & 0.72 & \\
\hline & \multicolumn{2}{|c|}{ Internal Carotid Law } & \multicolumn{2}{|c|}{ External Carotid Law } & \multicolumn{2}{|c|}{ Internal Carotid Left } & \multicolumn{2}{|c|}{ External Carotid Left } \\
\hline $\mathrm{cm} / \mathrm{sec}$ & MVS & VDF & MVS & VDF & MVS & VDF & MVS & VDF \\
\hline average & 30.65 & 7.80 & 20.46 & 7.24 & 29.41 & 7.89 & 19.77 & 6.92 \\
\hline SD & 21.45 & 2.77 & 5.05 & 2.26 & 8.81 & 2.74 & 3.63 & I.70 \\
\hline$(+)$ & 52.10 & 10.57 & 25.52 & 9.50 & 38.22 & 10.63 & 23.40 & 8.61 \\
\hline$(-)$ & 9.20 & 5.03 & $|5.4|$ & 4.97 & 20.60 & 5.14 & 16.14 & 5.22 \\
\hline \multirow[t]{2}{*}{ IR } & 0.75 & & 0.65 & & 0.73 & & 0.65 & \\
\hline & \multicolumn{2}{|c|}{ Primitive Carotid Law } & \multicolumn{2}{|c|}{ Primitive Carotid Left } & \multicolumn{2}{|c|}{ Cerebral Anterior Right } & \multicolumn{2}{|c|}{ Cerebral Anterior Eft } \\
\hline $\mathrm{cm} / \mathrm{sec}$ & MVS & VDF & MVS & VDF & MVS & VDF & MVS & VDF \\
\hline average & 28.05 & 6.90 & 26.63 & 6.07 & 29.9 & 17.0 & 28.3 & 15.9 \\
\hline SD & 8.00 & 3.50 & 8.30 & 3.04 & 0.93 & 0.70 & 0.64 & 0.91 \\
\hline$(+)$ & 36.05 & 10.40 & 34.93 & 9.47 & 35.13 & 8.79 & 34.00 & 10.03 \\
\hline$(-)$ & 20.05 & 3.40 & 18.33 & 3.30 & 19.31 & 3.48 & 18.66 & 3.17 \\
\hline IR & 0.75 & & 0.77 & & 0.51 & & 0.27 & \\
\hline
\end{tabular}

Cerebral anterior $=0.7861, \mathrm{p}<0.0001 ;$ Supratroclear $\mathrm{r}=0.2841, \mathrm{p}$ $<0.004$; Vertebral $\mathrm{R}=0.6341, \mathrm{p}<0.0001 ;$ Carotid $\mathrm{r}=0.8432, \mathrm{p}<0.0001$ MVS: Maximal Systolic Velocity; VDF: Final Diastolic Velocity; SD: Standard Deviation; IR: Resistance

\section{Conclusion}

Craniocorpography (CCG), Posturography (TOB), Electronystagmography (ENG), Rotatory Test (RIT), Optokinetic Test, Caloric Test and Doppler Ultrasonography are techniques for studying patients with vertigo. When analyzing what was studied and determined in these techniques we can find results in Mexico similar to the groups of Germany and Argentina.

The diagnosis of patients with vertigo in modern neuroneurological centers should include an anamnesis and exploration with objective and quantitative tests of balance, as well as complementary studies such as the circulatory hydrodynamic study through the Doppler Ultrasonography of Head and Neck for the best Diagnosis and treatment of the patient with vertigo.

\section{Acknowledgments}

None.

\section{Conflicts of interest}

None.

\section{Funding}

None.

\section{References}

1. Bergmann JM, Bertora GO. Skull-Corpographie-Muster beim Zustand nach Schadeltraumata. Verhdlg d GNA, Bd. VIII, 161-175. Edition edicim y Pharmacie, Hamburg und Neu-lsenburg, Germany. 1981.

2. Claussen CF. Skull-Body-Spray a body-wide target and Simple quantitative as well as intracorporeal posturography. Fr Symposium Posturographie international. Agressologie. 1981; 24(2):97-98.
3. Claussen CF, SA J. Clinical study of Human Equilibrium. Popular Observation on the directional preponderance of resulting caloric nystagmus of brain lesions. Brain. 1942;65:115-137.

4. Claussen CF Skull-Body-Graph. a simple and objective test of Detection of equilibrium. Prepr. Aerospace med. Ann. Scient. Meet. 1979;33:54

5. Claussen CF, SA J. Clinical study of Human Equilibrium by Electronystagmography and related tests. Popular Prakashan, Bombay, India. 1978.

6. Claussen, Bergmann J, Bertora GO. Equilibriometry and Tinnitology, Practice. COS Druck \& Verlag GmbH, Hersbruck, Germany. 2009.

7. Claussen CF, Scheineider D, Marcondes, LG, et al. A Computer Analysis of typical CCG patterns in 1021 otoneurological patients. Acta Oto Laringologica Suppl. 1989;468:235-238.

8. Claussen CF. Elektronystagmographie. Verhdlg D GNA, Bd Y, Verl. Edition Medicin and pharmacie, Frankfurt, Germany. 1975.

9. Claussen, CF, Aust G, Hortmann G, et al. Praktikum der Elektronystagmographie. Verhldg D GNA, Bd. II, Verl. Medical edition Pharmacie, Frankfurt, Germany. 1975.

10. Claussen CF, von Luhmann M Das. Elektronystagmogramm UN die Neurootologische Kennliniendiagnostik. Medicin and pharmacie edition, Hamburg UN Neu-Isenburg. 1976.

11. Claussen CF, Desa JV. A clinical study of human balance through Electronystagmography and allied tests. Popular Prakashan, Bombay, India. 1978.

12. Claussen CF. Das Frequenznystagmogramm, Eine quantitative einfache 3th Mexico. 1987. p.283-390.

13. Claussen CF. Eine Über Gleichgewichtsfunktionsprüfung Hilfe mit der Skull-Corpographie und im Polarkoorinaten Räume. Arch. Klin. exp. Or., Nas. -or. Kehlk. Heilk. 1970;196:256-261.

14. Claussen CF. Der rotatorische intensitätsdämpfungstest und seine Auswertung Mit Hilfeder L-schematics. Arch Klin Exp Or USA. Kehlk Heilk. 1971;197:351-360.

15. Said J, Izita A. New Techniques in The Diagnosis of Patients with vértigo. Annals of Mexican Otorhinolaryngology. 2011;56(1):1-10.

16. Said J, Izita A (2010) Test of balance study in patients with vertigo. Annals of Mexican Otorhinolaryngologia 55(4): 133-136. 
17. Glück W, Claussen CF, Kempf H, Breyer A (1981) Skull-BodyGraphische Untersuchungen des Kopf-Körper-Gleichgewichts bei Hochleitungsmonteuren. Verhdlg. D. GNA, Bd.1981; VIII: 265-284.

18. Said J, Izita A (2012) Results Comparisons of Craniocorpography and Posturography in Patients with Vertigo. Annals of Mexican Otorhinolaryngologia 57(2): 84-89.

19. Fukuda T. The Stepping Test: two Phases of the Labyrinth Reflex. Acta Otolaryngol 50(2): 95-108.

20. Claussen CF (1974) Die Skull-Body-Graphie. Arch Ohr Nas Kehlk Heilk I: 207

21. Claussen CF, Tato JM (1988) Practical equilibrium. Buenos Aires: Of Technique Topodiagnósticas y Terapéuticas. Edit. Springer-Verlag. Berlin, Germany.

22. Said J, Izita A, Gonzalez CA, Meneses A (1988) Craniocorpography in patients with Vertigo. Anales de Otorrinolaringologia Mexicana. XLIII(4): 179-183.

23. Unterberger S Neue registrierbare vestibularis-Körperdreh-Reaktionen.

24. Gurtu, JN (1997) Doppler Ultrasound in cerebral vascular disease Gazette Médica de México 133(5): 436-437.

25. Pessin MS, Daneault N, Kwan ES, Eisengart MA, Caplan LR (1988) local embolism from the Vertebral artery occlusion. Stroke 19(1): 112 125 .
26. Franke J, DI Marine V, Suitcase M, Argenson C, Libersa C (1981) The arteries Vertebral (artery vertebralis). The atlanto-axial V3 and V4 segments Intracranial collaterals. Anat Clin 2: 229.

27. LO Vuolo, M Gamas, Doppler (1997) Carotídos and Vertebrales. Ultamed. Escuela de Ultrasound and Doppler. Santa Fe, Argentina.

28. Needleman L (1993) Principles and artifacts in Doppler and Doppler color. Video library. Ultrasonica II Argentine Congress of Imaging. Buenos Aires, Argentina.

29. Saba P, Romana M, Pini R, Spitzer M, Ganau A, et al. (1993) Ventricular and the anatomy of the carotid in normal tense subjects. J of the College of Cardiology Amer 22: 7.

30. Taylor K, Burns P, Wells P (1988) Clinical applications of ultrasound Doppler. Raven Press. New York, USA.

31. Said J, Izita A (2016) Transcranial and extracranial doppler ultrasound and neck related to otoneurological tests in the patient with vértigo. Annals of Otorhinolaryngology Mexicana 61(2): 131-138.

32. Estol C, DE Witt L (1990) Tettenborn B: The accuracy of the transcranial doppler in the Vertebral basilar circulation. Ann Neurol 28: 225.

33. Bailao L, DO Prado J, Rizzi M, Bailao T, Herren H, et al. (1996) Fundamentals of ultrasonography. Diagnosis. Ribeirao Preto. Sao Paulo, Brazil.

34. Wayne WD (1999) Biostatistics. A foundation for analysis in the health sciences. (7th edn), J \& S. NY, USA. 